Article

\title{
New RO TFC Membranes by Interfacial Polymerization in $n$-Dodecane with Various co-Solvents
}

\author{
Abdullah Sulaiman Al-Hobaib ${ }^{1, *}$, Mohammed Sulaiman Al-Suhybani ${ }^{1}$, \\ Khalid Mohammed Al-Sheetan ${ }^{1}$, Hasan Mousa ${ }^{2,3, *}$ and Mohammed Rafi Shaik ${ }^{4, *}$ \\ 1 Nuclear Science Research Institute, King Abdulaziz City for Science and Technology (KACST), P.O. Box 6086, \\ Riyadh 11442, Saudi Arabia; sohybani@kacst.edu.sa (M.S.A.-S.); ksheetan@kacst.edu.sa (K.M.A.-S.) \\ 2 Department of Petroleum and Chemical Engineering, Sultan Qaboos University, P.O. Box 33, \\ Muscat 123, Oman \\ 3 Department of Chemical Engineering, Jordan University of Science and Technology, P.O. Box 3030, \\ Irbid 22110, Jordan \\ 4 Department of Chemistry, College of Sciences, King Saud University (KSU), P.O. Box 2455, \\ Riyadh 11451, Saudi Arabia \\ * Correspondence: ahobaib@kacst.edu.sa (A.S.A.-H.); hasana@squ.edu.om (H.M.); \\ rafiskm@gmail.com (M.R.S.); Tel.: +966-11-4813675 (A.S.A.-H.); +96-824142582 (H.M.); \\ +966-11-4670439 (M.R.S.); Fax: +966-11-4813690 (A.S.A.-H.); +96-824141354 (H.M.); +966-11-4674253 (M.R.S.)
}

Academic Editor: Isabel Coelhoso

Received: 10 March 2016; Accepted: 26 April 2016; Published: 29 April 2016

\begin{abstract}
The objective of this research is to prepare and characterize a new and highly efficient polyamide TFC RO membrane by interfacial polymerization in dodecane solvent mixed with co-solvents. Three co-solvents were tested namely; acetone, ethyl acetate, and diethyl ether of concentration of $0.5,1,2,3$, and 5 wt \%. The modified membranes were characterized by SEM, EDX, AFM and contact angle techniques. The results showed that addition of co-solvent results in a decrease in the roughness, pore size and thickness of the produced membranes. However, as the concentration of the co-solvent increases the pore size of the membranes gets larger. Among the three co-solvents tested, acetone was found to result in membranes with the largest pore size and contact angle followed by diethyl ether then ethyl acetate. Measured contact angle increases as the concentration of the co-solvent increases reaching a constant value except for ethyl acetate where it was found to drop. Investigating flux and salt rejection by the formulated membranes showed that higher flux was attained when acetone was used as a co-solvent followed by diethyl ether then ethyl acetate. However, the highest salt rejection was achieved with diethyl ether.
\end{abstract}

Keywords: interfacial polymerization; RO membrane; co-solvent; desalination

\section{Introduction}

Membranes are widely used in many industrial applications such as desalination and water treatment [1-4]. Different types of membranes were developed for oil-water separation [5-8], industrial waste water treatment $[9,10]$, organic matter removal from wastewater $[11,12]$ and municipal waste water treatment [13-16].

A persistent problem associated with the application of membrane processes is membrane fouling defined as the reduction in the flux through the membrane due to the blocking of its pores or constriction due to the deposition of small particles $[17,18]$. To minimize this problem researchers have worked on finding new ways to manufacture membranes in which fouling problem is minimized yet keeping high salt rejection. Some example of these techniques are those related to the incorporation of 
nanoparticles during membrane formulation [19-23], the graft polymerization of ionic liquids with nanoparticles [24], the addition of co-solvent during the manufacturing process [25], the fabrication electrically conductive membranes based on carbon nanostructures [26], the preparation of permeable zeolite membranes [27-29], the interfacial polymerization with natural material [29,30] and the use of hydrophilic modifier [6,7,31-36].

A Unique technique to accomplish a high degree of water permeability is to develop reactivity of the monomer with additives in the aqueous phase. For instance, Hirose et al. stated that the addition of ether and alcohol in the water phase headed to greater water permeability and greater salt rejection [37-39]. Zhao et al. also stated that addition of hydrophilic additives such as anthranilic acid in the water phase headed to greater water permeability and higher salt rejection [40]. However, only a small number of articles have ever stated about the membranes produced with additives in the organic phase.

In our other study, we have achieved that acetone, ethyl acetate, and diethyl ether as co-solvents with hexane based solvent resulted in excellent salt rejection and high permeability [41]. The aim of this research is to investigate the effect of using other base solvents such as dodecane with the above mentioned cosolvents on the performance of reverse osmosis (RO) membranes. The structure of the produced membrane will be characterized by SEM, EDX, AFM and contact angle techniques. To the best of our knowledge, this is the first attempt to prepare and characterize thin film composite reverse osmosis (TFC RO) membrane in dodecane mixed with cosolvent.

\section{Results and Discussion}

\subsection{SEM and EDX Analysis}

Scanning electron microscope (SEM) of the polysulfone (PS) membrane surface at magnification of $100 \mathrm{k}$ and $200 \mathrm{k}$ is reported in Figure $1 \mathrm{a}, \mathrm{b}$ respectively. It can be seen that the membrane surface is smooth.

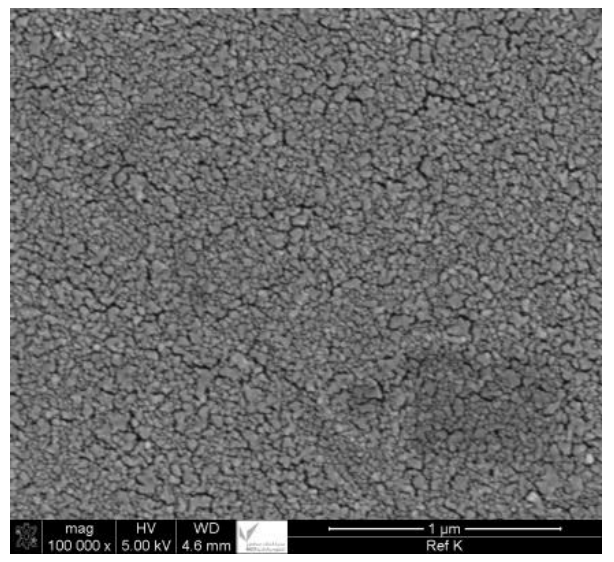

(a)

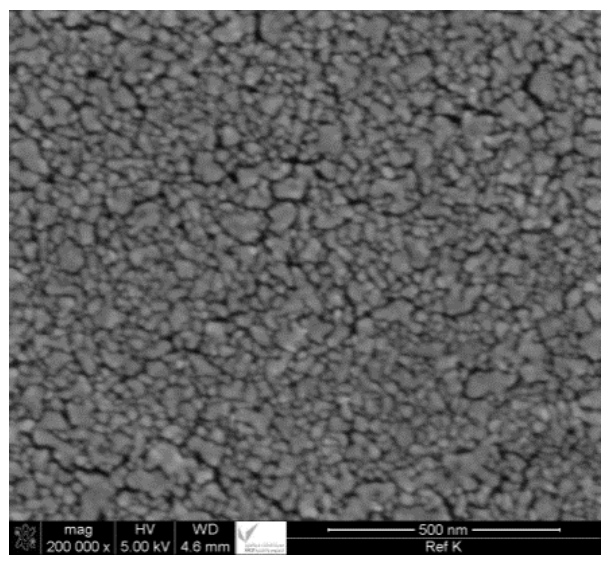

(b)

Figure 1. SEM images of PS membrane. (a) $100 \mathrm{k}$ and (b) $200 \mathrm{k}$ magnification.

Images of the TFC reference (FT-30 membrane) by EDX and SEM portrayed in Figure 2a,b show that the surface roughness ranges between 25 and $34 \mathrm{~nm}$. This is slightly rougher than that of the PS membrane (27-31 nm) [41] as indicated by the AFM images in Figure 3. The EDX spectrum shows that $\mathrm{C}, \mathrm{O}$, and $\mathrm{S}$ are the main elements exist in the TMC membrane.

The effect of adding co-solvents on the membrane morphology as shown has been investigated by SEM characterization (Figure $4 \mathrm{a}-\mathrm{c}$ ) for acetone, diethyl ether and ethyl acetate respectively. The images confirms the theory, i.e., that the addition of a co-solvent introduces pores in the resulting membrane and pore size is proportional to co-solvent concentration $[37,42-44]$. The images of the SEM shows 
that pore size of membranes formulated with dodecane is larger than that formulated with hexane. This is possibly because dodecane has a larger molecular volume $\left(0.2738 \mathrm{~m}^{3} / \mathrm{kmol}\right)$ than that of hexane $\left(0.1406 \mathrm{~m}^{3} / \mathrm{kmol}\right)$. Therefore, molecular volume of the co-solvents plays a role in the pore size where the larger the molecular volume the larger the pore size [45].

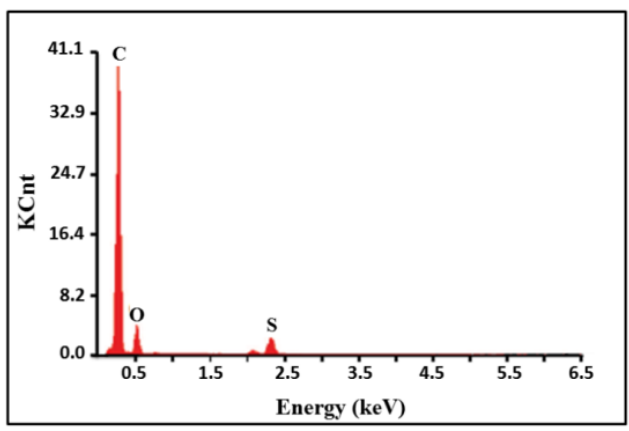

(a)

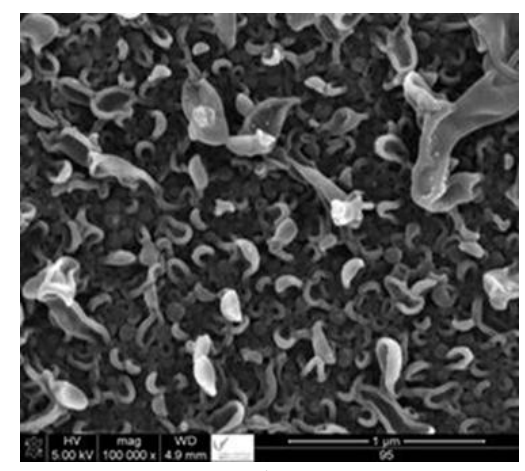

(b)

Figure 2. EDX spectrum (a) and (b) SEM image of TFC reference.

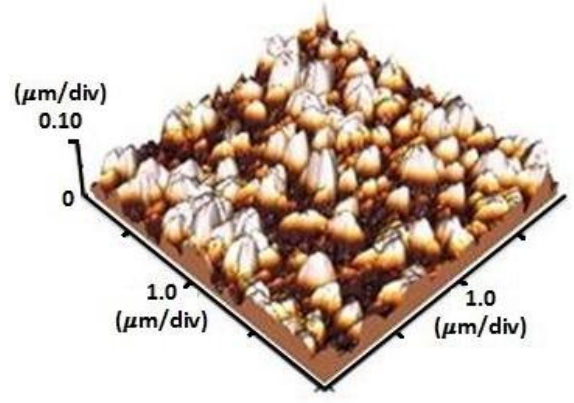

(a) TFC reference, $R_{a}=34 \mathrm{~nm}$

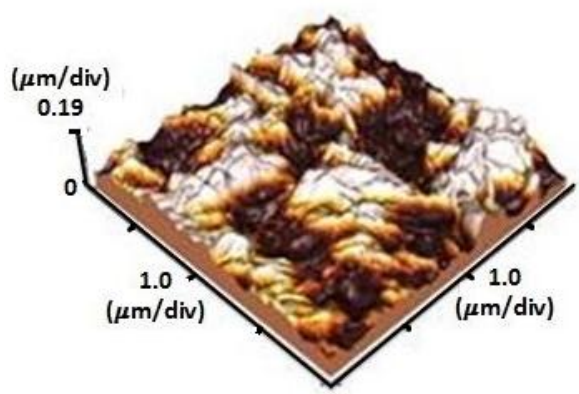

(c) Diethyl ether $2 \mathrm{wt} \%, R_{a}=32 \mathrm{~nm}$

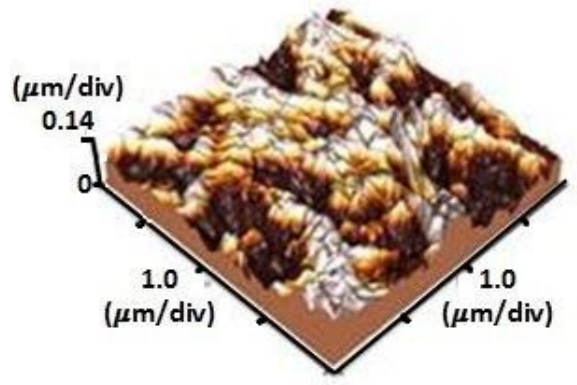

(b) Acetone $2 \mathrm{wt} \%, R_{a}=27 \mathrm{~nm}$

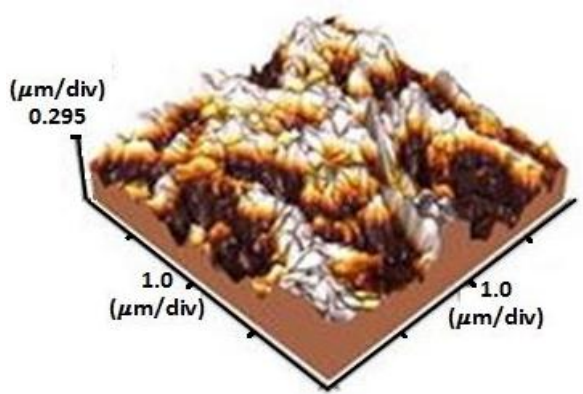

(d) Ethyl acetate $2 \mathrm{wt} \%, R_{a}=25 \mathrm{~nm}$

Figure 3. AFM images of formulated membranes with 2 wt \% of co-solvents added (a) no co-solvent added; (b) acetone; (c) diethyl ether; and (d) ethyl acetate.

The comparison of the surface morphology for the membranes prepared with two different solvent, i.e., hexane as reported in [41] and dodecane (this study), at a co-solvents concentration (acetone, diethyl ether and ethyl acetate) of 1\% is shown in Figure 5. The use of dodecane as solvent resulted in membrane with larger pore size (and hence the flux is expected to be larger as well) due to its reduced solubility (compared to hexane) with each of the three polar co-solvents giving to de-mixing phenomena [45]. Flux measurements and salt rejection are reported below in the permeate flux and salt rejection section. A comparison between the results of hexane and dodecane is reported and discussed as well. 


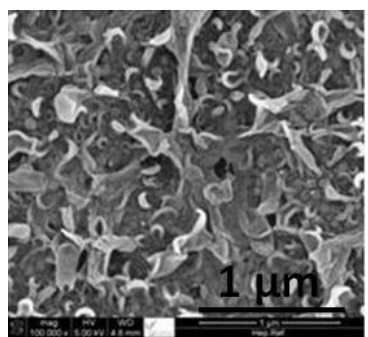

Conc. of Acetone $1 \mathrm{wt} \%$

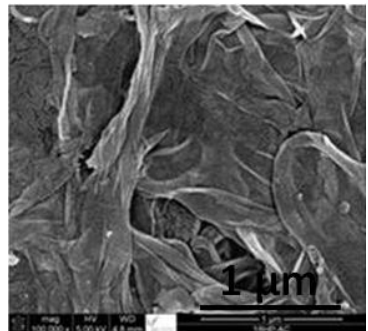

Conc. of Acetone 5 wt \%

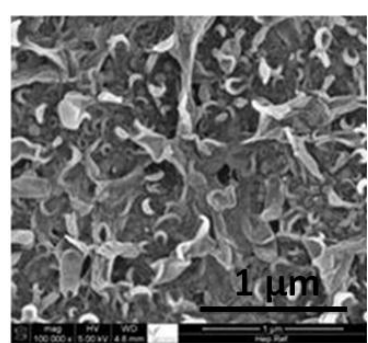

Diethyl ether $1 \mathrm{wt} \%$

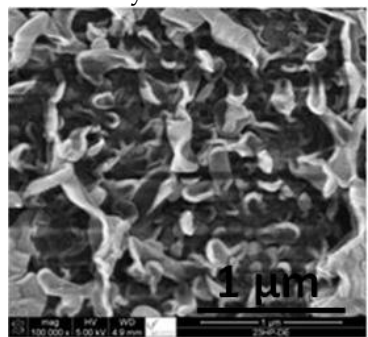

Diethyl ether 5 wt \%

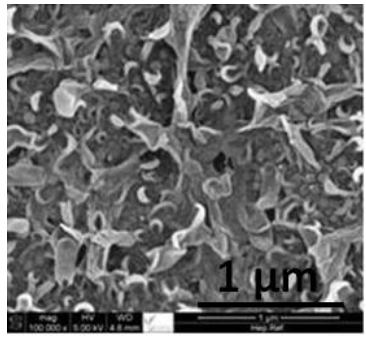

Ethyl acetate $1 \mathrm{wt} \%$

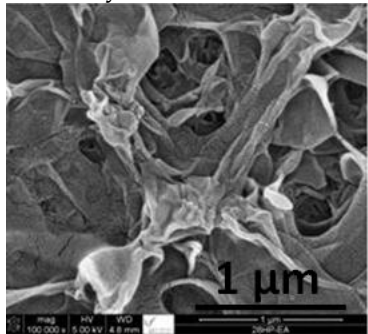

Ethyl acetate 5 wt \%

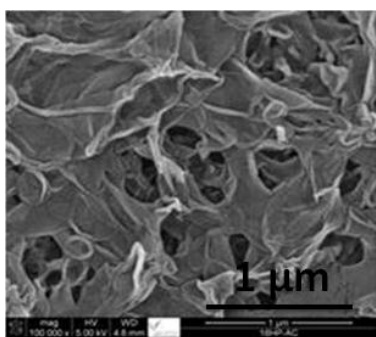

Conc. of Acetone 0.5 wt \%

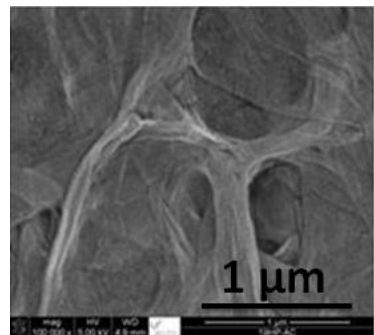

Conc. of Acetone $3 \mathrm{wt} \%$

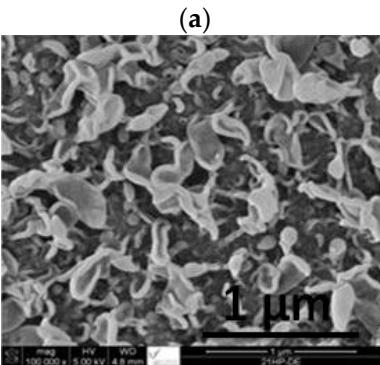

Diethyl ether $0.5 \mathrm{wt} \%$

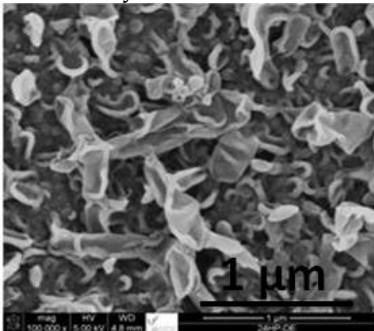

Diethyl ether $3 \mathrm{wt} \%$

(b)

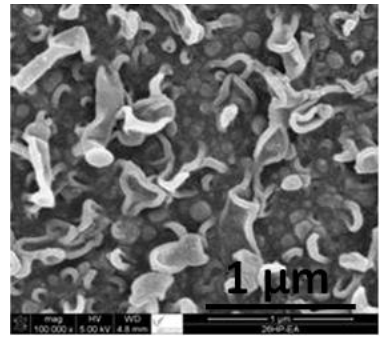

Ethyl acetate 0.5 wt \%

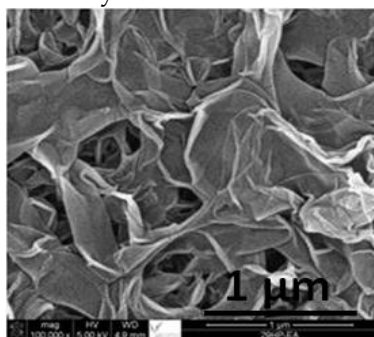

Ethyl acetate $3 \mathrm{wt} \%$

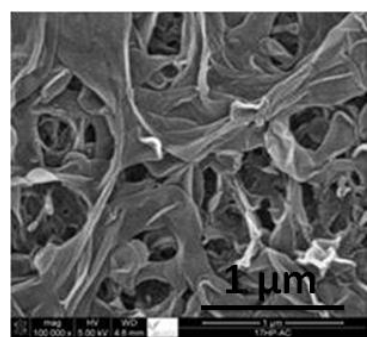

No additive

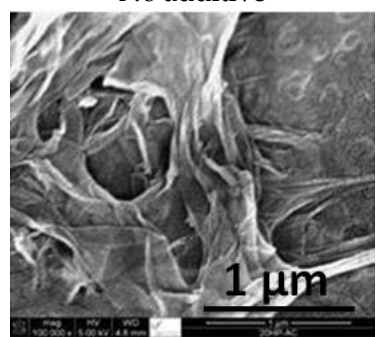

Conc. of Acetone $2 \mathrm{wt} \%$

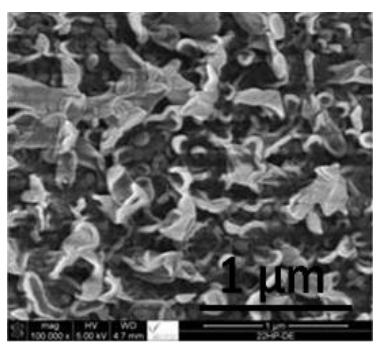

No additive

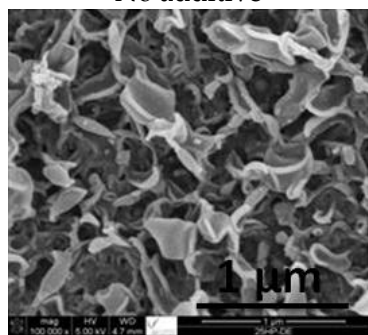

Diethyl ether 2 wt \%

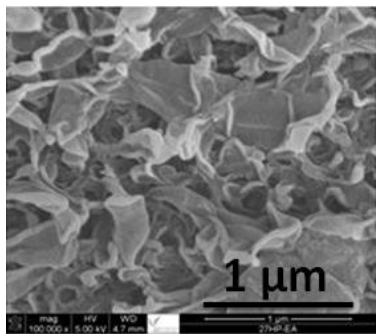

No additive

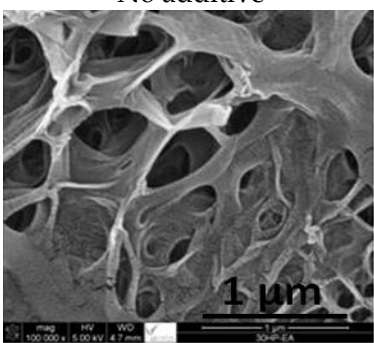

Ethyl acetate 2 wt \%

(c)

Figure 4. SEM images of the formulated membranes upon adding (a) acetone (b) diethyl ether (c) ethyl acetate. 

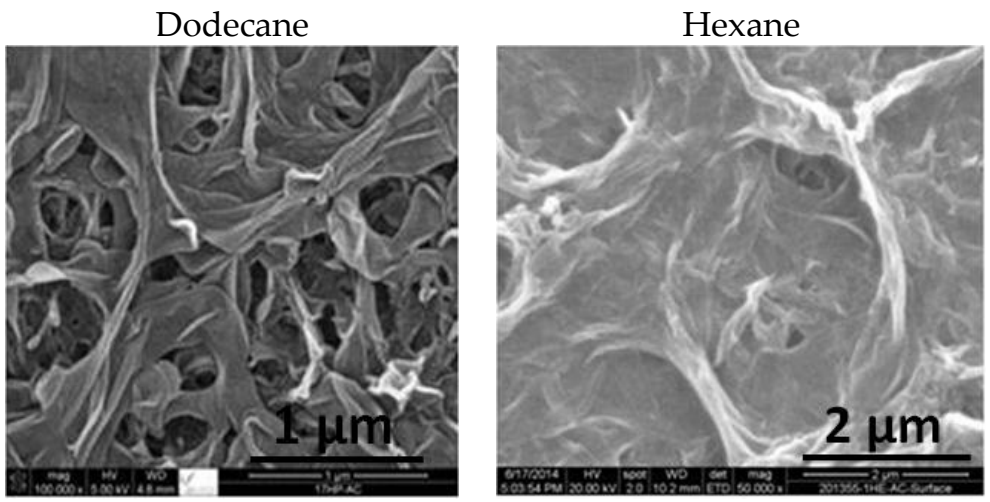

(a) Acetone $1 \%$
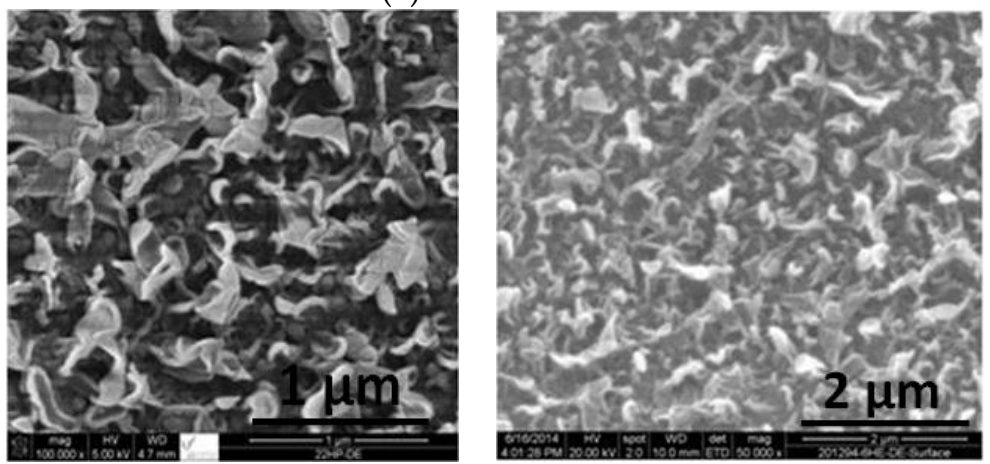

(b) Diethyl Ether 1\%
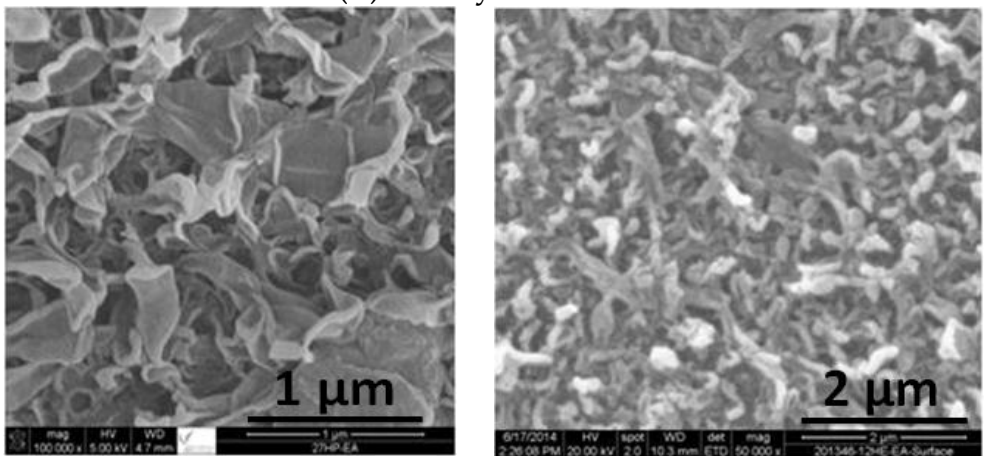

(c) Ethyl Acetate 1\%

Figure 5. A comparison between dodecane (left) and hexane (right) on the morphology of the formulated membranes with $1 \%$ co-solvent concentration (a) acetone; (b) diethyl ether and (c) ethyl acetate.

\subsection{Contact Angle Measurements}

Measured contact angles for the co-solvents added as a function of their concentration are shown in Figure 6. It can be seen that acetone gives the highest contact angle followed by diethyl ether and ethyl acetate. For all measured membranes, the contact angle is $<90^{\circ}$ indicating that they possess a hydrophilic property and hence they are less susceptible to fouling [46]. Figure 7 also shows that the contact angle for the three co-solvents tested goes through maxima at 1\% co-solvent concentration. A similar trend was obtained for hexane with smaller contact angle at $1 \%$ co-solvent concentration. However, at larger and smaller co-solvent concentrations, the contact angle for dodecane solvent is smaller [41]. 


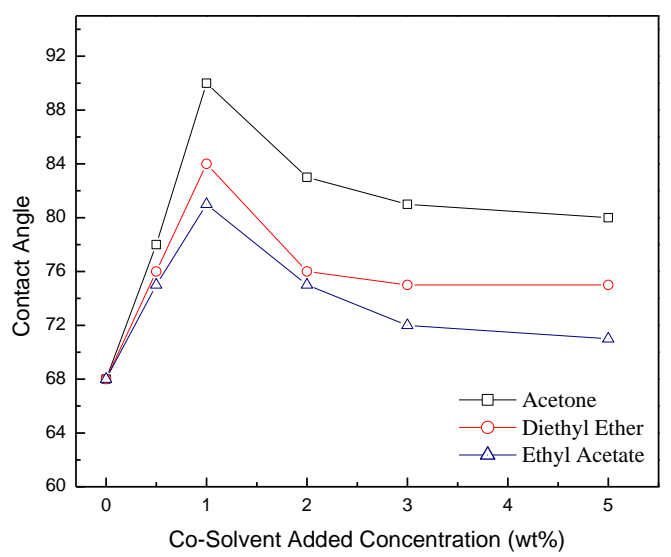

Figure 6. Contact angle as a function of co-solvent concentrations.

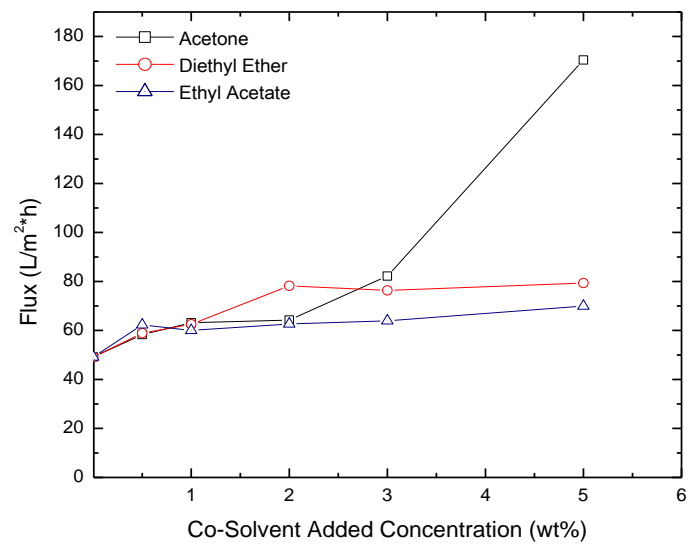

Figure 7. Flux of IPA through membranes formulated with acetone, diethyl ether and ethyl acetate added as co-solvents.

\subsection{Permeate Flux}

Measured permeate flux through the membranes as a function of the concentration of the co-solvent added is reported in Figures 7-9 for isopropyl alcohol (IPA), $\mathrm{NaCl}$ and $\mathrm{MgCl}_{2}$ solutions at a transmembrane pressure of $1.6 \times 10^{6} \mathrm{~Pa}$. The figures show that presence of the co-solvent increases the flux by $\sim 25 \%$. Except for acetone at concentration $>3 \%$, low effect of co-solvent concentration on flux was observed. From the SEM images above, Figure 5 shows that a large pore size membranes are obtained for acetone concentration $>3 \%$ explaining the fast increase in the flux. The comparison of the fluxes with those obtained for hexane solvent shows that dodecane based membranes yield higher flux for all the salts tested [41]. This is because formulated membranes using dodecane as a cosolvent have larger pore size compared to those formulated using hexane as a co solvent. A comparison between the fluxes through the two types of membranes for the IPA, $\mathrm{MgCl}_{2}$, and $\mathrm{NaCl}$ is shown in Table 1 .

Salt Rejection. Rejection of IPA, $\mathrm{NaCl}$ and $\mathrm{MgCl}_{2}$ salts as a function of co-solvent concentration is reported in Figures 10-12 respectively. The figures show that salt rejection follows the order: diethyl ether $>$ ethyl acetate $>$ acetone. This is not surprising since acetone yields the highest pore size followed by ethyl acetate then diethyl ether (Figure 5). The figures also show that co-solvent concentration adversely affects salt rejection due to the formation of larger pore size. The comparison of these results with those obtained with hexane based membranes shows that dodecane based membranes provide larger salt rejection [41]. A comparison between the values of salt rejection through the two types of membranes for the IPA, $\mathrm{MgCl}_{2}$, and $\mathrm{NaCl}$ is shown in Table 1 . 


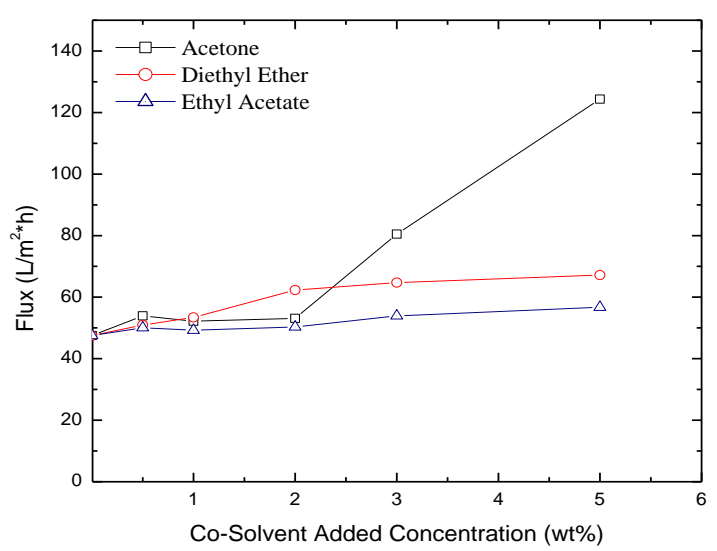

Figure 8. Flux of $\mathrm{NaCl}$ through membranes formulated with acetone, diethyl ether and ethyl acetate added as co-solvents.

Table 1. A comparison between the performance of hexane and dodecane based membranes. Data for hexane are obtained from Al-Hobaib et al. [41].

\begin{tabular}{|c|c|c|c|c|c|c|c|c|c|c|c|c|}
\hline \multicolumn{13}{|c|}{ Isopropanol (IPA) } \\
\hline \multirow{4}{*}{$(w t \%)$} & \multicolumn{12}{|c|}{ Co-Solvents Type } \\
\hline & \multicolumn{4}{|c|}{ Acetone } & \multicolumn{4}{|c|}{ Diethyl Ether } & \multicolumn{4}{|c|}{ Ethyl Acetate } \\
\hline & \multicolumn{2}{|c|}{$n$-Hexane } & \multicolumn{2}{|c|}{ n-Dodecane } & \multicolumn{2}{|c|}{$n$-Hexane } & \multicolumn{2}{|c|}{$n$-Dodecane } & \multicolumn{2}{|c|}{$n$-Hexane } & \multicolumn{2}{|c|}{ n-Dodecane } \\
\hline & $F$ & $S$ & $F$ & $S$ & $F$ & $S$ & $F$ & $S$ & $F$ & $S$ & $F$ & $S$ \\
\hline 0 & 26 & 95 & 49 & 96 & 26 & 95 & 49 & 96 & 27 & 95 & 49 & 96 \\
\hline 0.5 & 47 & 88 & 59 & 90 & 41 & 95 & 59 & 95 & 37 & 95 & 63 & 95 \\
\hline 1 & 51 & 83 & 64 & 86 & 46 & 93 & 63 & 95 & 40 & 92 & 62 & 95 \\
\hline 2 & 66 & 70 & 65 & 74 & 53 & 91 & 79 & 94 & 44 & 91 & 63 & 92 \\
\hline 3 & 76 & 42 & 83 & 45 & 54 & 91 & 77 & 92 & 48 & 80 & 64 & 80 \\
\hline \multicolumn{13}{|c|}{$\mathrm{NaCl}$} \\
\hline \multirow{4}{*}{$(w t \%)$} & \multicolumn{12}{|c|}{ Co-Solvents Type } \\
\hline & \multicolumn{4}{|c|}{ Acetone } & \multicolumn{4}{|c|}{ Diethyl Ether } & \multicolumn{4}{|c|}{ Ethyl Acetate } \\
\hline & \multicolumn{2}{|c|}{$n$-Hexane } & \multicolumn{2}{|c|}{ n-Dodecane } & \multicolumn{2}{|c|}{$n$-Hexane } & \multicolumn{2}{|c|}{$n$-Dodecane } & \multicolumn{2}{|c|}{$n$-Hexane } & \multicolumn{2}{|c|}{$n$-Dodecane } \\
\hline & $F$ & $S$ & $F$ & $S$ & $F$ & $S$ & $F$ & $S$ & $F$ & $S$ & $F$ & $S$ \\
\hline 0 & 26 & 99 & 47 & 99 & 26 & 99 & 47 & 98 & 27 & 98 & 47 & 98 \\
\hline 0.5 & 39 & 96 & 53 & 99 & 36 & 96 & 51 & 98 & 34 & 98 & 50 & 99 \\
\hline 1 & 41 & 93 & 53 & 98 & 41 & 96 & 54 & 98 & 38 & 97 & 50 & 98 \\
\hline 2 & 56 & 83 & 54 & 97 & 45 & 92 & 63 & 87 & 42 & 97 & 51 & 98 \\
\hline 3 & 67 & 37 & 81 & 97 & 42 & 80 & 65 & 82 & 44 & 98 & 54 & 97 \\
\hline \multicolumn{13}{|c|}{$\mathrm{MgCl}_{2}$} \\
\hline \multirow{4}{*}{ (wt \%) } & \multicolumn{12}{|c|}{ Co-Solvents Type } \\
\hline & \multicolumn{4}{|c|}{ Acetone } & & ieth & Eth & & & Ethy & Acet & \\
\hline & $n-\mathrm{H}$ & ane & $n$-D & ecane & $n-\mathrm{H}$ & ane & $n-\mathrm{D}$ & ecane & $n-\mathrm{H}$ & xane & $n-\mathrm{D}$ & cane \\
\hline & $F$ & $S$ & $F$ & $S$ & $F$ & $S$ & $F$ & $S$ & $F$ & $S$ & $F$ & $S$ \\
\hline 0 & 27 & 99 & 48 & 98 & 27 & 99 & 48 & 98 & 27 & 99 & 48 & 98 \\
\hline 0.5 & 41 & 97 & 62 & 98 & 42 & 98 & 54 & 98 & 35 & 95 & 54 & 99 \\
\hline 1 & 45 & 94 & 61 & 98 & 40 & 97 & 57 & 96 & 39 & 95 & 53 & 99 \\
\hline 2 & 56 & 88 & 63 & 97 & 47 & 96 & 64 & 96 & 44 & 92 & 54 & 98 \\
\hline 3 & 74 & 26 & 82 & 84 & 44 & 97 & 69 & 99 & 45 & 77 & 56 & 98 \\
\hline
\end{tabular}




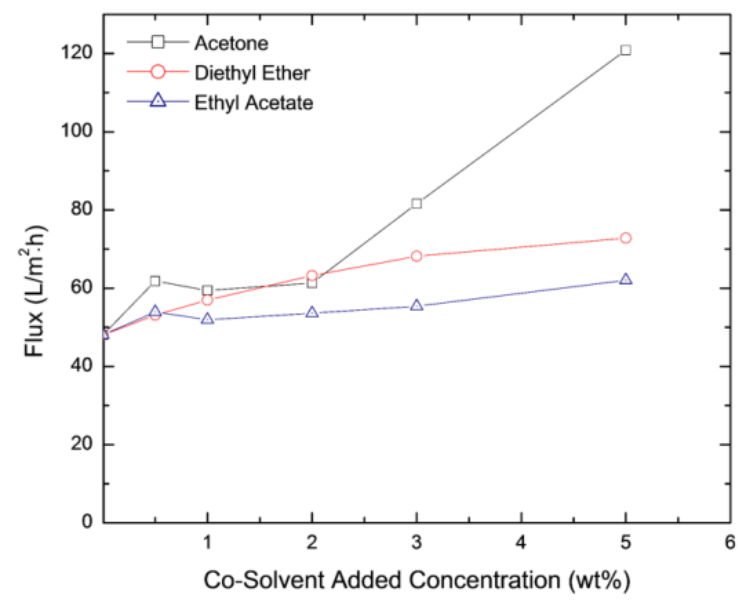

Figure 9. Flux of $\mathrm{MgCl}_{2}$ through membranes formulated with acetone, diethyl ether and ethyl acetate added as co-solvents.

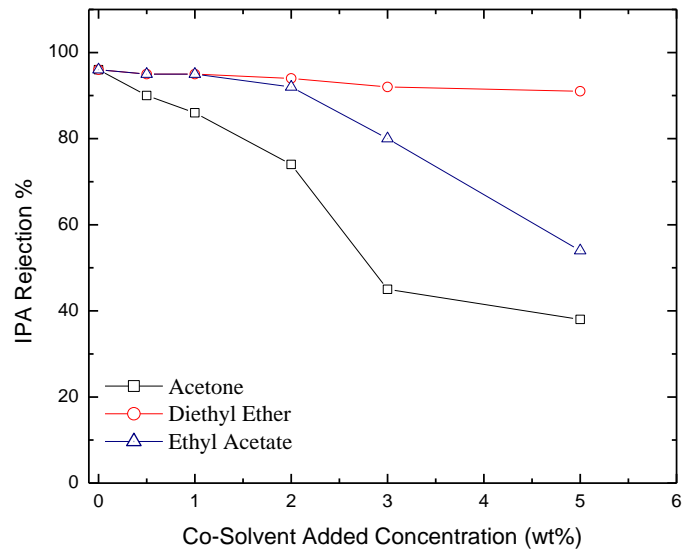

Figure 10. Salt rejection of IPA through membranes formulated with acetone, diethyl ether, and ethyl acetate added as co-solvents.

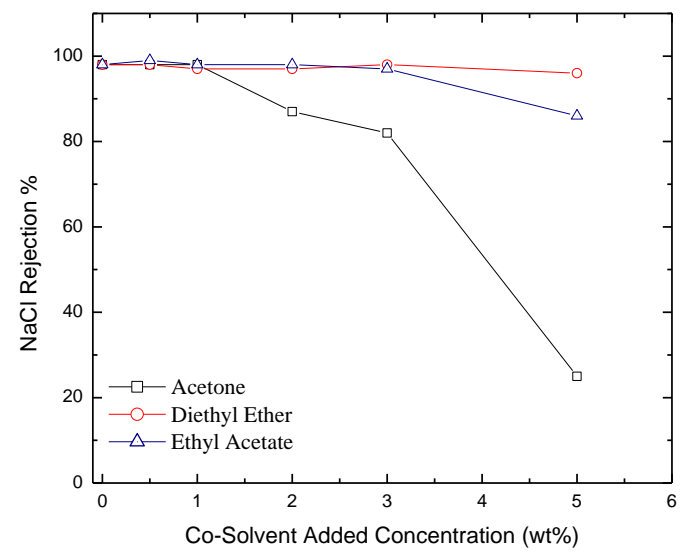

Figure 11. Experimentally measured salt rejection of $\mathrm{NaCl}$ through membranes formulated with acetone, diethyl ether, and ethyl acetate added as co-solvents. 


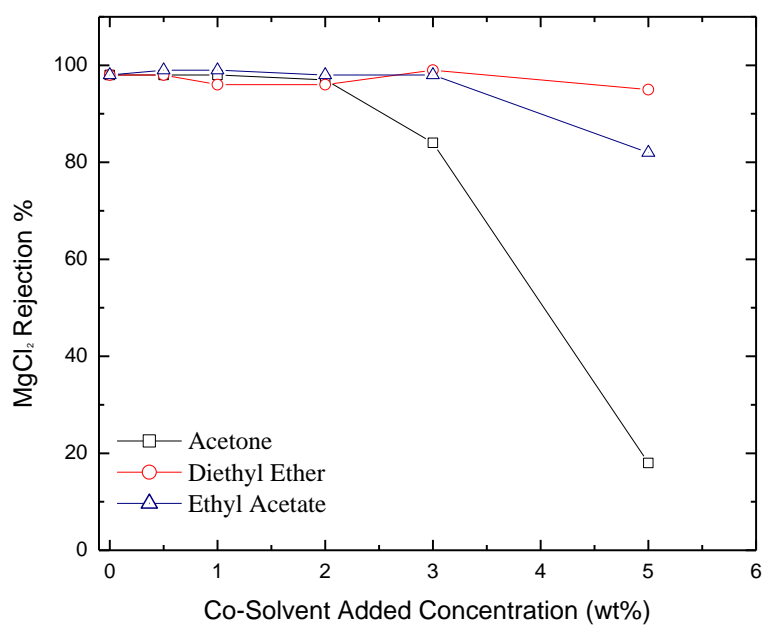

Figure 12. Salt rejection of $\mathrm{MgCl}_{2}$ through membranes formulated with acetone, diethyl ether, and ethyl acetate added as co-solvents.

\section{Experimental Section}

\subsection{Materials}

All of the chemicals and reagents used in this study were purchased at the highest purity grades available.

\subsection{Methods}

Preparation of Modified Polyamide Membranes

Polyamide nanocomposite membranes were prepared on an ultrafiltration polysulphone (PS-20, Sepro, Oceanside, CA, USA) The microporous polysulphone supporting film with molecular weight cut-off (MWCO) of $20 \mathrm{kDa}$ and Water Permeate Flux of $1000 \mathrm{LMH} /$ bar, (Sepro, Oceanside, CA, USA) has been used as base for polymerization of 1,3-phenylenediamine (MPD, >99\%, Sigma, St. Louis, MO, USA) with 1,3,5-benzenetricarbonyl trichloride (TMC, >98\%, Sigma, St. Louis, MO, USA). The polyamide TFC membrane was produced by immersing PS-20 in an aqueous solution of $2 \%$ MPD for $2 \mathrm{~min}$ (the excess MPD solution was removed by rubber roller). The membrane is then immersed in $0.1 \%$ TMC/Dodecane solution (99\%, Sigma) for $1 \mathrm{~min}$ with the required co-solvent. It is then rinsed with $0.2 \% \mathrm{Na}_{2} \mathrm{CO}_{3}(>99 \%$, Scharlau, Barcelona, Spain), washed with DI water, and finally stored in a refrigerator $\approx 4{ }^{\circ} \mathrm{C}$ in DI water until use. Acetone ( $>99 \%$, Sigma, St. Louis, MO, USA), ethyl acetate (>99\%, Sigma, St. Louis, MO, USA), and diethyl ether (>99\%, Sigma, St. Louis, MO, USA) were selected as co-solvents with mass fraction of $0.5 \mathrm{wt} \%, 1 \mathrm{wt} \%, 2 \mathrm{wt} \%, 3 \mathrm{wt} \%$ and $5 \mathrm{wt} \%$. The fabricated membranes were characterized by SEM, EDX, AFM and contact angle, (see next section for their specifications) to evaluate its performance with respect to salt rejection ability and water flux.

\subsection{Characterization and Instrumentation}

The following instrumentation techniques were used to characterize the developed membranes:

Scanning electron microscope (SEM) and energy-dispersive X-ray spectroscope (EDX). The morphology and microstructure of the as-synthesized TFC membranes were examined by scanning electron microscope (SEM, FEI Nova-Nano SEM-600, Eindhoven, The Netherlands). Quantitative analysis of the membranes was performed by energy-dispersive X-ray spectroscope (EDX).

Atomic force microscopy (AFM). Analysis of the surface morphology and roughness of the prepared membranes was performed by atomic force microscopy (AFM), using a Nan surf scanning 
probe-optical microscope (Bruker Corporation, Bremen, Germany). Small squares of the prepared membranes (approximately $1 \mathrm{~cm}^{2}$ ) were cut and glued onto glass substrates.

Contact angle. The contact angle was measured using a Ramé-Hart Model 250 Standard Goniometer/Tensiometer with DROP image Advanced software (Ramé-Hart Instrument Co., Succasunna, NJ, USA). A water droplet was placed on a dry flat homogeneous membrane surface and the contact angle between the water and membrane was measured until no further change was observed. The average contact angle for distilled water was determined in a series of eight measurements for each of the different membrane surfaces.

Cross-flow (flux and salt rejection). The performance of the prepared membranes was analyzed through a cross-flow system (CF042SS316 Cell, Sterlitech Corp., Kent, WA, USA). The active membrane area in this system was $42 \mathrm{~cm}^{2}$. The feed temperature was $25^{\circ} \mathrm{C}$ with the $\mathrm{pH}$ adjusted to $6.5 \pm 0.5$, $\mathrm{NaCl}$ concentration of $2000 \mathrm{ppm}$ and a flow rate of $3.8 \mathrm{~L} / \mathrm{min}$. The filtration was carried out at a transmembrane pressure of $1.6 \times 10^{6} \mathrm{~Pa}$. All measurements of the water flux and salt rejection were measured after $30 \mathrm{~min}$ of water filtration experiments to ensure that the system was at steady state. A schematic diagram of the cross-flow filtration system is shown in Figure 13.

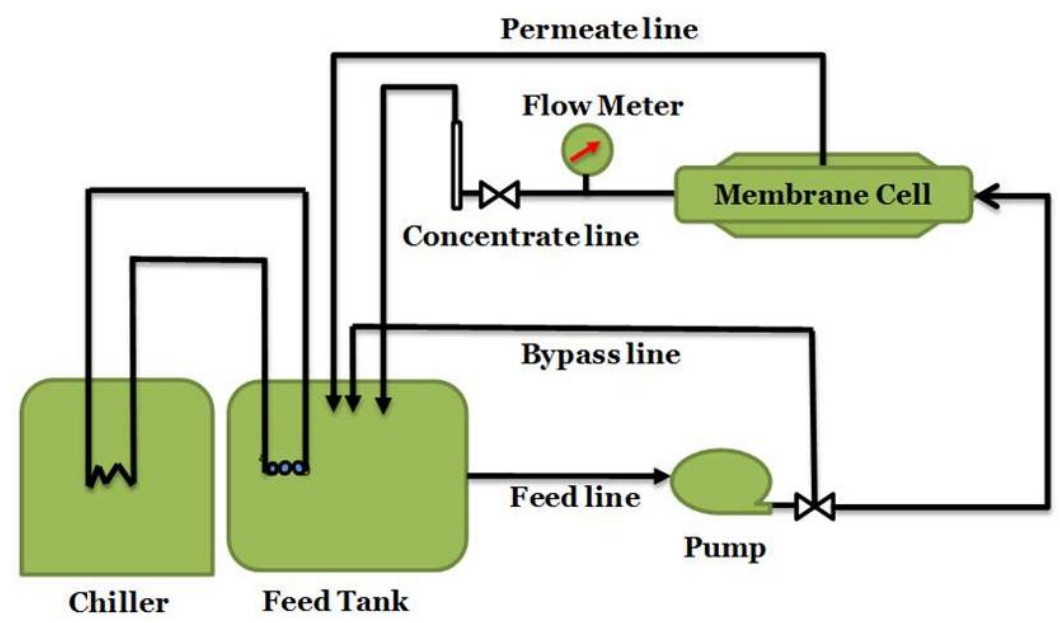

Figure 13. Schematic illustration of forward cross flow filtration system.

The flux was calculated from the following equation [15]

$$
J=\frac{V_{p}}{A \times t}
$$

where $J$ is the water flux $\left(\mathrm{L} \cdot \mathrm{m}^{-2} \cdot \mathrm{h}^{-1}\right), V_{p}$ is the permeate volume $(\mathrm{L}), A$ is the membrane area $\left(\mathrm{m}^{2}\right)$ and $t$ is the treatment time (h). Salt rejection (R) was calculated using the following equation:

$$
R=\left(1-\frac{C_{p}}{C_{f}}\right) \times 100
$$

where $C_{p}$ and $C_{f}$ are the salt concentrations in the permeate and feed, respectively.

\section{Conclusions}

Highly efficient polyamide TFC RO membranes based on dodecane mixed with acetone, diethyl ether, or ethyl acetate as co-solvent were formulated and evaluated. The results show that addition of co-solvent resulted in membranes that have large pore size, low thickness, and high contact angle. At a given concentration, the following (decreasing) trend in terms of pore size and flux for the membranes prepared with the three co-solvents has been observed: acetone > diethyl ether $>$ ethyl 
acetate. However, the highest IPA, $\mathrm{NaCl}$, and $\mathrm{MgCl}_{2}$ rejections were attained when diethyl ether was used as co-solvent. The contact angle increases as the concentration of co-solvent increases and reaches a plateau, except for ethyl acetate, for which it was found to decrease. The contact angle was largest when acetone as a co-solvent was used. The experimental results showed that dodecane based membranes have better performance compared to hexane based membranes.

Acknowledgments: The authors are grateful to King Abdulaziz City for Science and Technology, Riyadh, Saudi Arabia, for the financial support of this work and the facilities in its labs.

Author Contributions: Abdullah Sulaiman Al-Hobaib and Hasan Mousa designed the project, provided scientific guidance for successful completion of the project. Mohammed Rafi Shaik helped to draft the manuscript. Khalid Mohammed Al-Sheetan carried out the experimental part, synthesized the membrane and made its characterization. Mohammed Sulaiman Al-Suhybani and Mohammed Rafi Shaik carried out some of the characterizations and interpretation of the results.

Conflicts of Interest: The authors declare no conflict of interest.

\section{References}

1. Van der Bruggen, B.; Vandecasteele, C.; van Gestel, T.; Doyen, W.; Leysen, R. A review of pressure-driven membrane processes in wastewater treatment and drinking water production. Environ. Prog. 2003, 22, 46-56. [CrossRef]

2. Nicolaisen, B. Developments in membrane technology for water treatment. Desalination 2003, 153, 355-360. [CrossRef]

3. Rautenbach, R.; Vossenkaul, K.; Linn, T.; Katz, T. Waste water treatment by membrane processes-New development in ultrafiltration, nanofiltration and reverse osmosis. Desalination 1997, 108, 247-253. [CrossRef]

4. Garud, R.M.; Kore, S.V.; Kore, V.S.; Kulkarni, G.S. A short review on process and applications of reverse osmosis. Univers. J. Environ. Res. Technol. 2011, 1, 233-238.

5. Obaid, M.; Tolba, G.M.K.; Motlak, M.; Fadali, O.A.; Khalil, K.A.; Almajid, A.A.; Kim, B.; Barakat, N.A.M. Effective polyslufone-amorphous $\mathrm{SiO}_{2} \mathrm{NPs}$ electrospun nanofiber membrane for high flux oil/water separation. Chem. Eng. J. 2015, 279, 631-638. [CrossRef]

6. Zhang, J.; Seeger, S. Polyester materials with superwetting silicone nanofilaments for oil/water separation and selective oil absorption. Adv. Funct. Mater. 2011, 21, 4699-4704. [CrossRef]

7. Kong, J.; Li, K. Oil removal from oil-in-water emulsions using PVDF membranes. Sep. Purif. Technol. 1999, 16, 83-93. [CrossRef]

8. Zhang, F.; Zhang, W.B.; Shi, Z.; Wang, D.; Jin, J.; Jiang, L. Nanowire-haired inorganic membranes with superhydrophilicity and underwater ultralow adhesive superoleophobicity for high-efficiency oil/water separation. Adv. Mater. 2013, 25, 4192-4198. [CrossRef] [PubMed]

9. Qdais, H.A.; Moussa, H. Removal of heavy metals from wastewater by membrane processes: A comparative study. Desalination 2004, 164, 105-110. [CrossRef]

10. Dulneva, T.Y.; Kucheruk, D.D.; Goncharuk, V.V. Water purification of dyes by ceramic membranes modifed by $\mathrm{Fe}^{3+}$ hydroxocompounds. J. Water. Chem. Technol. 2015, 37, 85-89. [CrossRef]

11. Zularisam, A.W.; Ismail, A.F.; Salim, R. Behaviours of natural organic matter in membrane filtration for surface water treatment-A review. Desalination 2006, 194, 211-231. [CrossRef]

12. Mousa, H.A.; Al-Hitmi, S.A. Treatability of wastewater and membrane fouling. Desalination 2007, $217,65-73$. [CrossRef]

13. Wintgens, T.; Melin, T.; Schäfer, A.; Khan, S.; Muston, M.; Bixio, D.; Thoeye, C. The role of membrane processes in municipal wastewater reclamation and reuse. Desalination 2005, 178, 1-11. [CrossRef]

14. Tchobanoglous, G.; Darby, J.; Bourgeous, K.; McArdle, J.; Genest, P.; Tylla, M. Ultrafiltration as an advanced tertiary treatment process for municipal wastewater. Desalination 1998, 119, 315-321. [CrossRef]

15. Ćwikła, J.; Konieczny, K. Treatment of sludge water with reverse osmosis. Environ. Prot. Eng. 2011, 37, 21-34.

16. Cruver, J.E.; Nusbaum, I. Application of reverse osmosis to wastewater treatment. J. Water. Pollut. Control Fed. 1974, 46, 301-311. [PubMed]

17. Guo, W.; Ngo, H.-H.; Li, J. A mini-review on membrane fouling. Bioresour. Technol. 2012, 122, $27-34$. [CrossRef] [PubMed] 
18. Ren, H.; Wang, Q.; Zhang, X.; Kang, R.; Shi, S.; Cong, W. Membrane fouling caused by amino acid and calcium during bipolar membrane electrodialysis. J. Chem. Technol. Biotechnol. 2008, 83, 1551-1557. [CrossRef]

19. AL-Sheetan, K.M.; Shaik, M.R.; Al-Hobaib, A.S.; Alandis, N.M. Characterization and evaluation of the improved performance of modified reverse osmosis membranes by incorporation of various organic modifiers and $\mathrm{SnO}_{2}$ nanoparticles. J. Nanomater. 2015, 2015, 1-11. [CrossRef]

20. Fang, Y.; Duranceau, S.J. Study of the effect of nanoparticles and surface morphology on reverse osmosis and nanofiltration membrane productivity. Membranes 2013, 3, 196-225. [CrossRef] [PubMed]

21. AL-Hobaib, A.S.; AL-Sheetan, K.M.; El Mir, L. Effect of iron oxide nanoparticles on the performance of polyamide membrane for ground water purification. Mater. Sci. Semicond. Process. 2016, 42, 107-110. [CrossRef]

22. Jin, L.M.; Yu, S.L.; Shi, W.X.; Yi, X.S.; Sun, N.; Ge, Y.L.; Ma, C. Synthesis of a novel composite nanofiltration membrane incorporated $\mathrm{SiO}_{2}$ nanoparticles for oily wastewater desalination. Polymer 2012, 53, 5295-5303. [CrossRef]

23. Al-Hobaib, A.; AL-Sheetan, K.; Shaik, M.R.; Al-Andis, N.M.; Al-Suhybani, M.S. Characterization and evaluation of reverse osmosis membranes modified with $\mathrm{Ag}_{2} \mathrm{O}$ nanoparticles to improve performance. Nanoscale Res. Lett. 2015, 10,1-13. [CrossRef] [PubMed]

24. Yu, L.; Zhang, Y.; Zhang, H.; Liu, J. Development of a molecular separation membrane for efficient separation of low-molecular-weight organics and salts. Desalination 2015, 359, 176-185. [CrossRef]

25. Luo, R.-L.; Young, T.-H.; Sun, Y.-M. Structure formation and characterization of EVAL membranes with cosolvent of isopropanol and water. Polymer 2003, 44, 157-166. [CrossRef]

26. Lalia, B.S.; Ahmed, F.E.; Shah, T.; Hilal, N.; Hashaikeh, R. Electrically conductive membranes based on carbon nanostructures for self-cleaning of biofouling. Desalination 2015, 360, 8-12. [CrossRef]

27. Yan, H.; Ma, N.; Zhan, Z.; Wang, Z. Fabrication of zeolite NaA membranes on hollow fibers using nano-sized seeds exfoliated from mesoporous zeolite crystals. Microporous Mesoporous Mater. 2015, 215, $244-248$. [CrossRef]

28. Kazemimoghadam, M.; Mohammadi, T. Preparation of NaA zeolite membranes for separation of water/UDMH mixtures. Sep. Purif. Technol. 2006, 47, 173-178. [CrossRef]

29. Ma, J.; Shao, J.; Wang, Z.; Yan, Y. Preparation of zeolite NaA membranes on macroporous alumina supports by secondary growth of gel layers. Ind. Eng. Chem. Res. 2014, 53, 6121-6130. [CrossRef]

30. Zhou, C.; Shi, Y.; Sun, C.; Yu, S.; Liu, M.; Gao, C. Thin-film composite membranes formed by interfacial polymerization with natural material sericin and trimesoyl chloride for nanofiltration. J. Membr. Sci. 2014, 471, 381-391. [CrossRef]

31. Eren, E.; Sarihan, A.; Eren, B.; Gumus, H.; Kocak, F.O. Preparation, characterization and performance enhancement of polysulfone ultrafiltration membrane using PBI as hydrophilic modifier. J. Membr. Sci. 2015, 475, 1-8. [CrossRef]

32. Saffar, A.; Carreau, P.J.; Kamal, M.R.; Ajji, A. Hydrophilic modification of polypropylene microporous membranes by grafting $\mathrm{TiO}_{2}$ nanoparticles with acrylic acid groups on the surface. Polymer 2014, 55, 6069-6075. [CrossRef]

33. Gohari, R.J.; Korminouri, F.; Lau, W.J.; Ismail, A.F.; Matsuura, T.; Chowdhury, M.N.K.; Halakoo, E.; Gohari, M.S.J. A novel super-hydrophilic PSf/HAO nanocomposite ultrafiltration membrane for efficient separation of oil/water emulsion. Sep. Purif. Technol. 2015, 150, 13-20. [CrossRef]

34. Wang, L.; Wei, J.; Zhao, K.; Wu, B. Preparation and characterization of high-hydrophilic polyhydroxy functional PP hollow fiber membrane. Mater. Lett. 2015, 159, 189-192. [CrossRef]

35. Lv, Y.; Yang, H.-C.; Liang, H.-Q.; Wan, L.-S.; Xu, Z.-K. Nanofiltration membranes via co-deposition of polydopamine/polyethylenimine followed by cross-linking. J. Membr. Sci. 2015, 476, 50-58. [CrossRef]

36. Mansourpanah, Y.; Madaeni, S.S.; Adeli, M.; Rahimpour, A.; Farhadian, A. Surface modification and preparation of nanofiltration membrane from polyethersulfone/polyimide blend-Use of a new material (polyethyleneglycol-triazine). J. Appl. Polym. Sci. 2009, 112, 2888-2895. [CrossRef]

37. Kong, C.; Kanezashi, M.; Yamomoto, T.; Shintani, T.; Tsuru, T. Controlled synthesis of high performance polyamide membrane with thin dense layer for water desalination. J. Membr. Sci. 2010, 362, 76-80. [CrossRef]

38. Hirose, M.; Ito, H.; Kamiyama, Y. Effect of skin layer surface structures on the flux behavior of RO membranes. J. Membr. Sci. 1996, 121, 209-215. [CrossRef] 
39. Hirose, M.; Ito, H.; Maeda, M.; Tanaka, K. Highly Permeate Composite Reverse Osmosis Membrane, Method of Producing the Same, and Method of Using the Same. U.S. Patent 5,614,099, 25 March 1997.

40. Zhao, L.; Philip, C.-Y.; Chang, W.S.; Winston, H.O. High-flux reverse osmosis membranes incorporated with hydrophilic additives for brackish water desalination. Desalination 2012, 308, 225-232. [CrossRef]

41. AL-Hobaib, A.; Alsuhybani, M.; AL-Sheetan, K.M.; Mousa, H.; Shaik, M.R. Modification of thin-film composite polyamide membrane with co-solvents to improve performance. Anal. Methods 2016. submitted.

42. Kong, C.; Shintani, T.; Kamada, T.; Freger, V.; Tsuru, T. Co-solvent-mediated synthesis of thin polyamide membranes. J. Membr. Sci. 2011, 384, 10-16. [CrossRef]

43. Kamada, T.; Ohara, T.; Shintani, T.; Tsuru, T. Optimizing the preparation of multi-layered polyamide membrane via the addition of a co-solvent. J. Membr. Sci. 2014, 453, 489-497. [CrossRef]

44. Kamada, T.; Ohara, T.; Shintani, T.; Tsuru, T. Controlled surface morphology of polyamide membranes via the addition of co-solvent for improved permeate flux. J. Membr. Sci. 2014, 467, 303-312. [CrossRef]

45. Treybal, R.E. Mass Transfer Operations, 3rd ed.; McGraw Hill: New York, NY, USA, 1980.

46. Kumar, R.; Ismail, A.F. Fouling control on microfiltration/ultrafiltration membranes: Effects of morphology, hydrophilicity, and charge. J. Appl. Polym. Sci. 2015, 132, 1-20. [CrossRef]

(C) 2016 by the authors; licensee MDPI, Basel, Switzerland. This article is an open access article distributed under the terms and conditions of the Creative Commons Attribution (CC-BY) license (http://creativecommons.org/licenses/by/4.0/). 